\title{
Soroprevalência de Anaplasma marginale em bovinos da regiáo Centro-Sul do estado do Paraná, Brasil, por um teste imunoenzimático competitivo utilizando proteína recombinante MSP5-PR1
}

\author{
Seroprevalence of Anaplasma marginale in cattle from Center-South Region of Paraná State, \\ Brazil by a competitive ELISA test with recombinant MSP5-PR1 protein \\ Elizabete Regina Marangoni Marana' ${ }^{1}$; Juliana Alves Dias²; Roberta Lemos Freire'; \\ Josy Campanhã Vicentini ${ }^{3}$; Marilda Carlos Vidotto' ${ }^{1}$; Odilon Vidotto ${ }^{1 *}$
}

${ }^{1}$ Departamento de Medicina Veterinária Preventiva, Universidade Estadual de Londrina - UEL

${ }^{2}$ Pós-graduação em Ciência Animal, Universidade Estadual de Londrina - UEL

${ }^{3}$ Medicina Veterinária, Universidade Estadual de Londrina - UEL e Bolsista do Programa PBIC/UEL/CNPq

Recebido em 31 de Maio de 2008

Aceito em 27 de Fevereiro de 2009

\section{Resumo}

Foi determinada a prevalência de Anaplasma marginale em 223 soros de bovinos com idade maior ou igual a dois anos, das regióes de Ponta Grossa, Guarapuava e Laranjeiras do Sul, regiáo Centro-Sul do estado do Paraná. O teste imunoenzimático de competição PR1 (cELISA-PR1) foi utilizado para determinar a presença ou ausência de anticorpos anti- $A$. marginale. Dos 223 soros analisados, 130 (58,74\%) foram positivos pelo cELISA-PR1, sugerindo ser essa regiáo de instabilidade de enzoótica, com uma porcentagem significativa de animais susceptíveis à infecção por $A$. marginale, com risco potencial para desenvolver a anaplasmose. As características de tipo de exploraçáo da propriedade, sistema de criaçáo, manejo e forma de comercialização dos animais foram avaliadas. A análise estatística não demonstrou haver diferença significativa entre as variáveis estudadas e a positividade dos animais.

Palavras-chave: Anaplasma marginale, MSP5-PR1, cELISA, soroprevalência, bovino.

\begin{abstract}
Anaplasma marginale prevalence was determined in 223 sera samples in 2-year old or older cattle, from the CenterSouthern Region of the Paraná State, including Ponta Grossa, Guarapuava and Laranjeiras do Sul municipalities. A survey of antibodies IgG class against Anaplasma marginale was performed through a competitive immune absorbent assay (cELISA-PR1). From the 223 sera examined, 130 (58.74\%) reacted to cELISA-PR1 test, suggesting an region of enzootic instability, with a significant percentage of animals susceptible to infection by $A$. marginale and potentially in risk to develop anaplasmosis. The kind of exploration in the property, the breeding and handling system, the presence of other animals (ovine/caprine, horses, wild animals), and means of commercialization of animals were analyzed. The statistical analysis showed that there were no significant differences among the analyzed variables.
\end{abstract}

Keywords: Anaplasma marginale, MSP5-PR1, cELISA, seroprevalence, cattle.

\section{Introduçáo}

A anaplasmose bovina é uma doença causada pelo Anaplasma marginale (Ordem Rickettsiales, Família Anaplasmataceae) (DUMLER et al., 2001), que afeta principalmente regióes tropicais e subtropicais (KREIER; RISTIC, 1981), causando anemia, icterícia, perda de peso, aborto e mortes. Dessa forma,

\footnotetext{
*Autor para correspondência: Odilon Vidotto

Departamento de Medicina Veterinária Preventiva, Universidade Estadual

de Londrina - UEL, Campus Universitário, CP 6001, CEP 86051-990,

Londrina - PR, Brasil; e-mail: vidotto@uel.br
}

acarreta perdas econômicas na bovinocultura de carne e de leite (PALMER, 1989), podendo alcançar 500 milhóes de dólares anualmente (GRISI et al., 2002).

No estudo da anaplasmose, diferentes testes sorológicos têm sido utilizados e comparaçóes foram realizadas entre eles, como Fixação de Complemento - FC (RODGERS et al., 1994), Teste Aglutinação do Cartâo - TAC (PEREZ et al., 1994), Imunofluorescência Indireta - IFI (FRAGADA; CORDOVÉS; 
PUENTES, 1991) e ELISA (NIELSEN et al., 1996), TAC e IFI (KNOWLES et al., 1982), FC, TAC e IFI (BUNDY et al., 1983), IFI e ELISA (JONGEJAN et al., 1988), cELISA (KNOWLES et al., 1996), cELISA e TAC (MOLLOY et al., 1999).

No Brasil, os estudos para avaliar a prevalência da anaplasmose bovina em diferentes regióes constataram que a infecção está disseminada pelo país, o que evidencia a necessidade de desenvolvimento de melhores métodos de diagnóstico e medidas de controle para a doença. Araújo et al. (1995) encontraram 97,6\% de animais soropositivos na Bahia, utilizando o Teste de Conglutinação Rápida - TCR; no estado de Sergipe, pelo esfregaço sanguíneo, Oliveira et al. (1992) encontraram 12,3\%; Madruga et al. (2000) encontraram, respectivamente, pela IFI e ELISA, 97,2 e 96,9\% de animais soropositivos em região de estabilidade enzoótica do estado da Bahia e Yoshihara et al. (2003), utilizando um teste de ELISA por competição (cELISA), identificaram $76,1 \%$ de animais sororreagentes para $A$. marginale, na regiāo de Umuarama, Paraná.

O cELISA utiliza como antígeno a proteína recombinante de $19 \mathrm{kDa}$ do $A$. marginale (MSP5), e o anticorpo monoclonal ANAF16C1 ligado à peroxidase como conjugado (KNOWLES et al., 1996). Isolados de $A$. marginale de diferentes regióes do Brasil foram analisados por Western Blotting, e a MSP5 se mostrou conservada em todos (KANO et al., 2002). Estudo realizado em rebanhos leiteiros da região de Londrina identificou 92,94\% de animais soropositivos, sugerindo que essa é uma área de estabilidade enzoótica (ANDRADE et al., 2001). Estudos realizados em rebanhos de gado de corte da região de Umuarama, estado do Paraná, mostraram que $76,10 \%$ dos animais eram reagentes ao teste cELISA, sugerindo que essa região apresenta-se como área de instabilidade enzoótica (YOSHIHARA et al., 2003).

$\mathrm{O}$ presente trabalho teve como objetivo avaliar a prevalência da anaplasmose bovina na região Centro-Sul do Paraná, utilizando o teste de ELISA competitivo com rMSP5-PR1 (cELISA-PR1).

\section{Material e Métodos}

\section{Região estudada e amostragem}

O delineamento amostral foi elaborado em duas etapas, pelo Departamento de Defesa Animal - MAPA em colaboração com o Setor de Epidemiologia da Secretaria de Agricultura e Abastecimento do estado do Paraná - SEAB. Primeiro, uma seleção aleatória de um número pré-estabelecido de propriedades, que representam as unidades primárias de amostragem. Dentro das unidades primárias, com a finalidade de avaliar o estado sanitário do rebanho, foi amostrado de forma aleatória um número pré-estabelecido de animais (unidades secundárias). Os soros bovinos foram colhidos e armazenados no Laboratório de Microbiologia (Tabela 1) do Departamento de Medicina Veterinária Preventiva, UEL. Foram colhidos 1.970 soros bovinos das Regionais da SEAB de Ponta Grossa, Guarapuava e Laranjeiras do Sul, na região Centro-Sul do estado do Paraná (Figura 1), dos quais foram amostrados 223 soros bovinos sorteados sistematicamente. $\mathrm{O}$ tamanho da amostra foi calculado adotando-se uma prevalência de $80 \%$, precisão de $5 \%$ e nível de significância de 5\%.

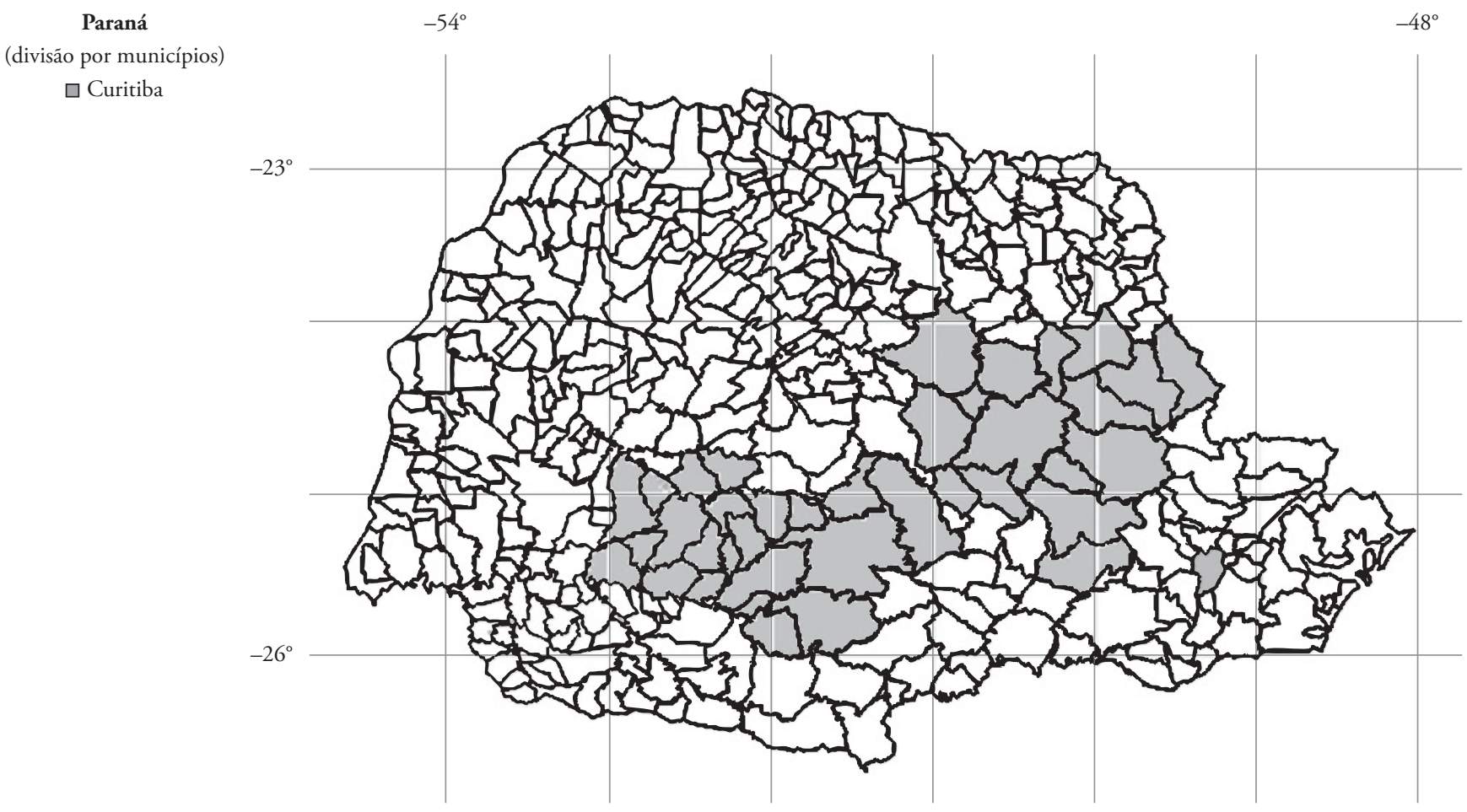

Figura 1. Mapa do estado do Paraná, demonstrando o circuito produtor e núcleos regionais de Ponta Grossa, Guarapuava e Laranjeiras do Sul - Secretaria de Agricultura e Abastecimento (SEAB - PR). 
Tabela 1. Número de propriedades, número total de bovinos maiores de 24 meses no circuito $4^{*}$ de produtores do estado do Paraná (2001a), das regionais de Ponta Grossa, Guarapuava e Laranjeiras do Sul, número de animais e propriedades amostradas pela SEAB - PR.

\begin{tabular}{|c|c|c|c|c|c|}
\hline \multicolumn{6}{|c|}{ Amostragem } \\
\hline \multicolumn{3}{|c|}{ Tipo de exploraçáo das propriedades (n) } & \multicolumn{3}{|c|}{ Total (n) } \\
\hline Corte & Leite & Mista & Propriedades amostradas & Animais amostrados & $\begin{array}{l}\text { Amostragem de animais } \\
\text { por sorteio sistemático }\end{array}$ \\
\hline 69 & 112 & 117 & 298 & 1970 & 223 \\
\hline
\end{tabular}

${ }^{2}$ Fonte Paraná, 2001. *Possui propriedades cujo tipo de exploração não foi informado.

\section{Questionário}

Para a obtenção dos dados epidemiológicos utilizou-se um questionário preenchido no ato da coleta de cada amostra de sangue, cuja finalidade foi levantar informações sobre o ambiente de produção, produtos e aspectos sanitários da propriedade.

\section{ELISA de competição com a proteina recombinante rMSP5-PR1}

Foi empregada a proteína rMSP-PR1 como antígeno, segundo Knowles et al. (1996), com modificaçóes. A concentração da proteína utilizada foi $2 \mu \mathrm{g} / 100 \mu \mathrm{L} /$ por cavidade. Os soroscontrole e testes foram adsorvidos com lisado de E. coli BL21 Star (DE3) One Shot ${ }^{\mathrm{TM}}$ na concentração de $0,22 \mu \mathrm{g} / \mathrm{ML}$, em tampão de conjugado (salina tamponada de fosfato de potássio $0,5 \mathrm{M} \mathrm{pH} \mathrm{7,2} \mathrm{-} \mathrm{PPBS} \mathrm{-} \mathrm{com} \mathrm{1 \%} \mathrm{de} \mathrm{leite} \mathrm{desnatado),} \mathrm{em} \mathrm{volumes}$ iguais $(120 \mu \mathrm{L})$ e incubados por 30 minutos. $\mathrm{O}$ conjugado monoclonal ANAF16C1-HRPO anti-MSP5 produzido em camundongo foi adicionado na diluiçáo de 1:12.000, em tampão de conjugado $\mathrm{pH} 7,2$ com $5 \%$ de leite desnatado e incubado por 10 minutos em temperatura ambiente sob agitação e adicionados $100 \mu \mathrm{L} /$ cavidade do substrato $o$-fenilenediamina di-hidroclorídrico (OPD - SIGMA P-6912) com peróxido de hidrogênio.

A determinação da porcentagem de inibição, representando um resultado positivo no cELISA, foi obtida a partir de 135 soros negativos da região livre de anaplasmose, Santa Vitória do Palmar, RS, abaixo do Paralelo $32^{\circ} \mathrm{S}$, sendo determinada a partir da densidade óptica (DO) a $490 \mathrm{~nm}$ em leitor de ELISA Bio-Tek Instruments ${ }^{\oplus}$, INC Modelo ELx 800) com DO média de 0,890, com um desvio padrão (DP) de $\pm 0,018$. Um valor de três $\mathrm{DP}$ abaixo da $\mathrm{DO}$ $(0,647)$ representou $27 \%$ de inibição (MARANA, 2006). Os resultados foram expressos como porcentagem de inibição baseado na fórmula: $100-\left[\left(\mathrm{DO}_{490}\right.\right.$ média do soro teste $\left.\mathrm{x} 100\right) /$ média da $\mathrm{DO}_{490}$ do controle negativo] (TORIONI DE ECHAIDE et al., 1998).

\section{Análise estatística}

Foram tabulados os dados das DOs dos soros-teste obtidos no cELISA em leitor de ELISA, calculadas as médias e submetidos à análise estatística pelo teste de Qui-Quadrado e Odds Ratio, mediante o programa Epi Info versão 6.04 (DEAN et al., 1994). Adotaram-se $95 \%$ de nível de confiança. A análise do perfil de estabilidade e instabilidade enzoótica foi efetuada segundo Mahoney e Ross (1972).

\section{Resultados e Discussáo}

Os 223 soros analisados (Tabela 1) apresentaram 131 soros positivos, resultando numa prevalência de 130 (58,74\%). Esse valor foi menor que os 92,94\% de Andrade et al. (2001), dos $87,5 \%$ de Vidotto et al. (1998) encontrados na região de Londrina, no Norte do estado do Paraná, e dos 76,10\% de Yoshihara et al. (2003), utilizando-se o cELISA, na região de Umuarama, Noroeste do estado do Paraná.

Anaplasma marginale possui na sua membrana, dentre outras, a proteína MSP5, a qual se encontra altamente conservada nos isolados de $A$ marginale, $A$. centrale e $A$. ovis de várias regióes geográficas (VISSER et al., 1992). Kano et al. (2002) observaram sua presença nos isolados Flórida, Mato Grosso do Sul, São Paulo, Minas Gerais, Paraná e Rio Grande do Sul. O cELISA-PR1 utilizou como antígeno a rMSP5-PR1 do isolado PR1 de $A$. marginale, com ponto discriminativo de $27 \%$ de inibição. Assim os $58,74 \%$ dos bovinos da região Centro-Sul do estado do Paraná estudados foram soropositivos, apresentando porcentagem de inibição $\geq 27,11 \%$. Esses resultados demonstraram uma prevalência menor quando comparados às regióes Norte e Noroeste do estado do Paraná. Esse fato aconteceu, provavelmente, por causa das diferenças de temperatura e umidade entre essas regióes, que poderiam interferir no desenvolvimento do vetor Rhipicephalus Boophilus microplus, sugerindo região de instabilidade enzoótica de acordo com o critério estabelecido por Mahoney e Ross (1972).

Diferentes autores, estudando o comportamento da anaplasmose bovina, encontraram variaçóes na taxa de prevalência, tais como 1,17 a 2,49\% na Suíça (DREHER et al., 2005); $0,89 \%$ nas regiōes áridas e montanhosas da Arábia Saudita (EL-METENAWY, 2000); 31 a 37\% no semi-árido de Idaho, EUA (MAAS et al., 1986); 6 a 32\% em diferentes regióes bolivianas (MAS et al., 2000) e de 80 a 99\% nas regióes tropicais (PATARROYO; VIAS; GRANADO, 1978; KNOWLES et al., 1982; PAYNE; OSORIO, 1990; COSSIO-BAYÚGAR et al., 1997). Os 58,74\% de prevalência, encontrados neste trabalho, mostraram que, no ambiente subtropical da região Centro-Sul do estado do Paraná, a prevalência da anaplasmose bovina apresentou oscilação, mostrando valores mais baixos quando comparados àqueles de regióes mais quentes do estado.

No Brasil, estudos com soros bovinos da regiáo Norte Fluminense, RJ mostraram que a prevalência da anaplasmose bovina variou entre 88,57 e $92,94 \%$, com diferença significativa entre os municípios de área de instabilidade enzoótica, (SOUZA et al., 2000). Na região de estabilidade enzoótica semi-árida do 
Tabela 2. Resultados sorológicos de bovinos da região Centro-Sul do Paraná (2005), obtidos pelo cELISA-PR1 contra rMSP5-PR1 de Anaplasma marginale, associados com características de exploração, submetidos à análise estatística pelos testes de Qui-Quadrado e Odds Ratio.

\begin{tabular}{|c|c|c|c|c|}
\hline Variáveis & $\begin{array}{c}\text { Amostras } \\
\text { positivas/total (\%) }\end{array}$ & Qui-quadrado $\left(\chi^{2}\right)$ & Valor de P & OR (IC95\%) \\
\hline \multicolumn{5}{|l|}{ Tipo de exploração } \\
\hline corte & $40 / 74(54,05)$ & 1,070 & 0,590 & $\mathrm{NC}$ \\
\hline leite & $48 / 77(62,34)$ & - & - & - \\
\hline mista & $40 / 69(57,97)$ & - & - & - \\
\hline \multicolumn{5}{|l|}{ Tipo de Criação } \\
\hline confinado & $1 / 1(100)$ & 0,740 & 0,690 & $\mathrm{NC}$ \\
\hline semi-confinado & $21 / 35(60)$ & - & - & - \\
\hline extensivo & $109 / 187(58,29)$ & - & - & - \\
\hline \multicolumn{5}{|l|}{ Número de ordenha } \\
\hline $1 \times$ ao dia & $55 / 103(53,40)$ & 4,950 & 0,080 & $\mathrm{NC}$ \\
\hline $2-3 \times$ ao dia & $41 / 58(70,70)$ & - & - & - \\
\hline não ordenha & $33 / 60(55,00)$ & - & - & - \\
\hline \multicolumn{5}{|l|}{ Tipo de ordenha } \\
\hline manual & $80 / 135(59 / 26)$ & 3,020 & 0,390 & $\mathrm{NC}$ \\
\hline mecânica ao pé & $15 / 23(65,22)$ & - & - & - \\
\hline mecânica em sala de ordenha & $5 / 6(83,33)$ & - & - & - \\
\hline não ordenha & $29 / 56(51,79)$ & - & - & - \\
\hline \multicolumn{5}{|l|}{ Inseminação (IA) } \\
\hline monta natural & $8 / 15(53,33)$ & 0,900 & 0,825 & $\mathrm{NC}$ \\
\hline IA e monta natural & $16 / 25(64,00)$ & - & - & - \\
\hline usa só IA & $103 / 175 /(58,87)$ & - & - & - \\
\hline \multicolumn{5}{|l|}{ Raça } \\
\hline zebu & $29 / 50(58,00)$ & 7,380 & 0,117 & $\mathrm{NC}$ \\
\hline europeu de leite & $33 / 57(57,89)$ & - & - & - \\
\hline europeu corte & $10 / 27(37,04)$ & - & - & - \\
\hline mestiço & $50 / 80(62,50)$ & - & - & - \\
\hline outras raças & $5 / 6(83,33)$ & - & - & - \\
\hline \multicolumn{5}{|l|}{ Compra de animais } \\
\hline $\operatorname{sim}$ & $81 / 138(58,70)$ & 0,000 & 0,985 & 0,97 \\
\hline não & $50 / 84(59,52)$ & - & - & $(0,53<\mathrm{OR}<1,75)$ \\
\hline \multicolumn{5}{|l|}{ De onde } \\
\hline exposição & $2 / 2(100)$ & 2,170 & 0,539 & $\mathrm{NC}$ \\
\hline leilão/feira & $2 / 5(40,00$ & - & - & - \\
\hline comerciante de gado & $9 / 15(60,00)$ & - & - & - \\
\hline de outras propriedades & $66 / 110(60,00)$ & - & - & - \\
\hline \multicolumn{5}{|l|}{ Venda de animais } \\
\hline $\operatorname{sim}$ & $36 / 53(67,92)$ & 0,163 & 1,950 & 1,67 \\
\hline não & $95 / 170(55,88)$ & - & - & $(0,83<\mathrm{OR}<3,40)$ \\
\hline \multicolumn{5}{|l|}{ Para onde } \\
\hline exposição & $2 / 2(100)$ & 3,020 & 0,389 & $\mathrm{NC}$ \\
\hline leilāo/feira & $2 / 5(40,00$ & - & - & - \\
\hline comerciante de gado & $9 / 15(60,00)$ & - & - & - \\
\hline de outras propriedades & $66 / 110(60,00)$ & - & - & - \\
\hline
\end{tabular}

$\mathrm{P}=$ probabilidade; $\mathrm{NC}=$ nâo calculado . 
Tabela 3. Resultados sorológicos de A. marginale nos bovinos da região Centro-Sul do Paraná (2005), associando a presença ou ausência de outras espécies animais na propriedade, sistema de piquete para pastagem, à análise estatística pelos testes de Qui-Quadrado e Odds Ratio.

\begin{tabular}{|c|c|c|c|c|}
\hline Variáveis & $\begin{array}{c}\text { Soros bovinos } \\
\text { positivos/total (\%) }\end{array}$ & Qui-quadrado $\left(\chi^{2}\right)$ & Valor de P & OR (IC95\%) \\
\hline \multicolumn{5}{|l|}{ Outros animais } \\
\hline não & $4 / 7(57,14)$ & & & $(0,18<\mathrm{OR}<5,91)$ \\
\hline \multicolumn{5}{|l|}{ Ovinos/caprinos } \\
\hline \multicolumn{5}{|l|}{ Equídeos } \\
\hline presença & $99 / 171(57,74)$ & 1,81 & 0,404 & 0,73 \\
\hline ausência & $33 / 52(63,46)$ & & & $(0.35<\mathrm{OR}<1.49)$ \\
\hline \multicolumn{5}{|l|}{ Suínos } \\
\hline presença & $121 / 203(59,61)$ & 0,35 & 0,552 & 1,48 \\
\hline ausência & $10 / 20(50,00)$ & & & $(0,53<\mathrm{OR}<4,08)$ \\
\hline \multicolumn{5}{|l|}{ Cão/gato } \\
\hline presença & $123 / 210(58,57)$ & 0,01 & 0,936 & 0,88 \\
\hline ausência & $8 / 13(61,54)$ & & & $(0,24<\mathrm{OR}<3,14)$ \\
\hline \multicolumn{5}{|l|}{ Animais silvestres } \\
\hline presença & $63 / 105(60,00)$ & 0,02 & 0,901 & 1,07 \\
\hline ausência & $67 / 115(58,26)$ & & & $(0,60<\mathrm{OR}<1,92)$ \\
\hline \multicolumn{5}{|l|}{ Cervídeos } \\
\hline presença & $30 / 51(58,82)$ & 0,00 & 0,971 & 1,09 \\
\hline ausência & $34 / 60(56,67)$ & & & $(0,48<\mathrm{OR}<2,52)$ \\
\hline \multicolumn{5}{|l|}{ Aluga pasto } \\
\hline $\operatorname{sim}$ & $32 / 51(62,74)$ & 0,31 & 0,575 & 1,27 \\
\hline não & $97 / 170(57,06)$ & & & $(0,63<\mathrm{OR}<2,55)$ \\
\hline \multicolumn{5}{|l|}{ Pasto em comum } \\
\hline $\operatorname{sim}$ & $29 / 47(61,70)$ & 0,05 & 0,830 & 1,14 \\
\hline não & $102 / 174(58,62)$ & & & $(0,46<\mathrm{OR}<2,34)$ \\
\hline \multicolumn{5}{|l|}{ Piquete de parição } \\
\hline $\operatorname{sim}$ & $41 / 70(58,57)$ & 0,01 & 0,912 & 0,99 \\
\hline não & $90 / 153(58,82)$ & & & $(0,53<\mathrm{OR}<1,84)$ \\
\hline \multicolumn{5}{|l|}{ Veterinário } \\
\hline $\operatorname{sim}$ & $35 / 65(53,84)$ & 0,56 & 0,455 & 0,77 \\
\hline não & $92 / 153(60,13)$ & & & $(0,41<\mathrm{OR}<1,44)$ \\
\hline \multicolumn{5}{|l|}{ Tipo } \\
\hline cooperativa & $10 / 17(58,82)$ & 0,00 & 0,975 & 1,20 \\
\hline particular & $25 / 46(54,35)$ & & & $(0,34<\mathrm{OR}<4,33)$ \\
\hline
\end{tabular}


estado da Bahia, em quatro municípios estudados, foi encontrado 94,8 e $97 \%$ de prevalência, utilizando-se dois sistemas de ELISA (BARROS et al., 2005). A região Norte do Paraná apresentou $67,38 \%$ dos bovinos positivos analisados pela IFI (VIDOTTO et al., 1995) e 87,5\% de bovinos positivos pelo cELISA (VIDOTTO et al., 1998). A taxa de soroprevalência de $58,74 \%$ encontrada mostrou-se inferior àquelas encontradas em outras regióes do Brasil, demonstrando que, à medida que se avança para o sul do país, as condiçóes climáticas vão se alterando e a prevalência da anaplasmose diminuindo.

Os resultados obtidos através da aplicação de questionário epidemiológico foram analisados associados com o estudo das variáveis apresentadas nas Tabelas 2 e 3, observando-se que não apresentaram resultados significativos no teste de Qui-Quadrado, com $\mathrm{P}=0,01$ e intervalo de confiança de $95 \%$, quanto às diferentes características dos rebanhos e do sistema de manejo.

A raça dos animais não apresentou influência nos resultados, embora se tenha observado que os animais mestiços apresentaram um pequeno aumento na soropositividade (Tabela 2). Por outro lado, Vidotto et al. (1998) analisaram animais de raça leiteira (Bos taurus) e animais cruzados (Bos taurus/Bos indicus) e encontraram taxa de soropositividade de 87,56\%; Andrade et al. (2001) examinaram somente raças leiteiras (Bos taurus), obtendo 92,94\% de soropositivos; e Yoshihara et al. (2003) encontraram um valor menor $(76,88 \%)$, estudando bovinos de corte da raça Nelore (Bos indicus). Fatores que devem ter influenciado essas diferenças são as raças e variaçóes climáticas entre as regióes Norte e Central que podem interferir na maior ou menor população de vetores.

O sistema de comercialização do gado, a utilização de piquetes comuns por diferentes rebanhos, aluguel de pasto, piquetes de parição, presença ou a ausência de animais silvestres, como cervídeos, capivara e outros animais nas propriedades, também não apresentaram diferença significativa no teste do Qui-Quadrado (Tabelas 2 e 3).

\section{Conclusão}

Assim, com a prevalência de 58,74\%, avaliada através do cELISA-PR1, em 223 soros bovinos, a regiáo Sul, do estado do Paraná, apresentou-se como área de instabilidade enzoótica sendo necessária a observação quanto à infestação de carrapatos e seu controle, atenção quanto à manifestação de sinais clínicos, com animais parcialmente imunizados contra $A$. marginale e susceptíveis a surtos de anaplasmose. As características de tipo de exploração da propriedade, sistema de criação, manejo e forma de comercialização dos animais foram avaliadas.

\section{Referências}

ANDRADE, G. M. et al. Soroprevalência de Anaplasma marginale em bovinos leiteiros e estudos sobre a dinâmica da infecção natural em bezerros holandeses no Sul do Brasil. Semina: Ciências Agrárias, v. 22, n. 2, p. 155-159, 2001.

ARAÚJO, F. R. et al. Levantamento sorológico para Anaplasma marginale em duas microrregióes do estado da Bahia. Revista Brasileira de Parasitologia Veterinária, v. 4, n. 2, supl. 1, p. 188, 1995.
BARROS, S. L. et al. Serological survey of Babesia bovis, Babesia bigemina and Anaplasma marginale antibodies in cattle from semi-arid region of state of Bahia, Brazil, by enzyme-linked immunosorbent assays. Memórias do Instituto Oswaldo Cruz, v. 100, n. 6, p. 513-517, 2005.

BUNDY, D. A. P.; HYlTON, G. A.; WAGNER, G. G. Bovine haemoparasitic diseases in Jamaica. Tropical Animal Health and Production, v. 15, n. 1, p. 47-48, 1983.

COSSÍO-BAYÚGAR, R. et al. Bovine anaplasmosis prevalence in Northern Vera Cruz State, Mexico. Preventive Veterinary Medicine, v. 32, n. 2, p. 165-170, 1997.

DEAN, A. G. et al. Epi Info, Version 6: a word processing, database, and statistic program for epidemiology on microcomputers. Atlanta, Georgia: Center for Diseases Control and Prevention, 1994. Disponível em: <http//:www.cdc.gov.>. Acesso em: Oct 2005.

DREHER, U. M. et al. Seroprevalence of anaplasmosis among cattle in Switzerland in 1998 and 2003: No evidence of an emerging disease. Veterinary Microbiology, v. 107, n.1, p. 71-79, 2005.

DUMLER, J. S. et al. Reorganization of genera in the families Rickettiaceae and Anaplasmataceae in the order Rickettsiales: unification of some species of Ehlrlichia with Anaplasma, Cowdria with Ehrlichia and Ehrlichia with Neorickettsia, descriptions of six new species combinations and designation of Ehrlichia equi and 'HGE agent' as subjective synonyms of Ehrlichia phagocytophila. International Journal of Systematics and Evolucionary Microbiology, n. 51, n. 4, p. 2145-2165, 2001.

EL-METENAWY, T. M. Prevalence of blood parasites among cattle at the central area of Arabia Saudita. Veterinary Parasitology, v. 87, n. 2-3, p. 231-236, 2000.

FraGADA, M.; CORDOVES, C. O.; PUENTES, T. Circulación de anticuerpos de hemoparásitos en ganado (Bos taurus) de alto valor genético en la República de Cuba. Revista Cubana de Ciencias Veterinarias, v. 22, n. 3, p. 249-255, 1991.

GRISI, L. et al. Impacto econômico das principais ectoparasitoses em bovinos no Brasil. Hora Veterinária, v. 21, n. 1, p. 8-10, 2002.

IBGE. Paranacidade, 2005. Disponível em: <http://www.ibge.gov.br/ http://www.paranacidade.org.br/municipios/select_municipios.hpwww. pr.gov.br, http://www.ipardes.gov.br/.>. Acesso em: Dez 2005.

JONGEJAN, F. et al. Epidemilogy of bovine babesiosis and anaplasmosis in Zambia. Tropical Animal Health and Production, v. 20, n. 4, p. 234-242, 1988.

KANO. S. F. et al. Antigenic characterizations of Anaplasma marginale isolates from different regions of Brazil. Veterinary Microbiology, n. 87, n. 2, p. 131-138, 2002.

KNOWLES, R. T. et al. Clinical and serological evidence of bovine babesiosis and anaplasmosis in St. Lúcia. Veterinary Parasitology, v. 10, n. 4, p. 307-311, 1982.

KNOWLES, D. P. et al. Antibody against an Anaplasma marginale MSP5 epitope common to tick and erythrocyte stages identifies persistently infected cattle. Infection and Immunity, v. 34, n. 9, p. 2225-2230.

KREIER, J. P.; RISTIC, M. The biology pof hemotrophic bacteria. Annual Review Microbiology, v. 35, p. 325-338, 1981.

MAAS, J. et al. Epidemiologic aspects of bovine anaplasmosis in semiarid range conditions of south central Idaho. American Journal of Veterinary Research, v. 47, n. 5, p. 528-533, 1986. 
MADRUGA, C. R. et al. Evaluation of an enzyme linked immunosorbent assay to detect antibodies against Anaplasma marginale. Pesquisa Veterinária Brasileira, v. 20, n. 3, p. 109-112, 2000.

MAHONEY. D. F.; ROSS, D. R. Epizootiological factors in control of bovine babesiosis. Australian Veterinary Journal, v. 48, n. 5, p. 292-298, 1972.

MAS, J. J. H. et al. Risk of babesiosis and anaplasmosis in different ecological zones of Santa Cruz. Veterinary Parasitology, v. 93, n. 1, p. 29-38, 2000.

MARANA, E. R. M. Padronização e Avaliação de um Teste de ELISA competitivo modificado para o diagnóstico da anaplasmose bovina, baseado na Proteína Recombinante MSP5-PR1. Londrina, 2006. 80f. Tese (Doutorado em Ciências Animal) - Universidade Estadual de Londrina.

MOLLOY, J. B. et al. Comparison of a competitive inhibition ELISA and the card agglutination test for detection of antibodies to Anaplasma marginale and Anaplasma centrale in cattle. Australian Veterinary Journal, v. 77, n. 4, p. 245-249, 1999.

NIELSEN, K. et al. Development and validation of an indirect enzyme immunoassay for detection of antibody to Anaplasma marginale in bovine sera. Veterinary Parasitology, v. 67, n. 3-4, p. 133-142, 1996.

OLIVEIRA, A. A. et al. Doenças de bezerros. II. Epidemiologia da anaplasmose no estado de Sergipe. Arquivos Brasileiros de Medicina Veterinária e Zootecnia, v. 44, n. 5, p. 377-386, 1992.

PALMER, G. H. Anaplasma vaccines. In: WRIGHT, I. G. (ed.). Veterinary Protozoan and Hemoparasite Vaccines. Boca Raton: CRC Press, 1989. p. 1-29.

PATTARROYO, J. H.; VILLA, O.; DIAZ GRANADOS, H. Epidemiology of cattle anaplasmosis in Colombia. I. Prevalence and distribution of agglutinating antibodies. Tropical Animal Health and Production, v. 10, n. 3, p. 171-174, 1978.
PAYNE, R. C.; OSÓRIO, O. Tick-borne diseases of cattle in Paraguay.I. Seropidemiological studies on anaplasmosis and babesiosis. Tropical Animal Health and Production, v. 22, n. 1, p. 53-60, 1990.

PEREZ, E. et al. Epidemilogy of bovine anaplasmosis and babesiosis in Costa Rica. Preventive Veterinary Medicine, v. 20, n. 1-2, p. 23-31, 1994.

RODGERS, S. J. et al. Seroprevalence of bovine anaplasmosis in Oklahoma from 1977 to 1991 . Journal of Veterinary Diagnostic Investigation, v. 6, n. 2, p. 200-208, 1994.

SOUZA, J. C. P. et al. Soroprevalência de Anaplasma marginale em bovinos na mesorregiâo Norte Fluminense. Pesquisa Veterinária Brasileira, v. 20, n. 3, p. 97-101, 2000.

TORIONI DE ECHAIDE, S. et al. Detection of cattle neturally infected with Anaplasma marginale in a region of endemicity by nested PCR and competitive enzyme linked immunosorbent assay using recombinant major surface protein-5. Journal of Clinical Microbiology, v. 36, n. 3, p. $777-782,1998$.

VIDOTTO, M.C. et al. Seroprevalence of Anaplasma marginale in cattle in Paraná State, Brazil, by MSP-5 competitive ELISA. Annals of New York Academy of Sciences, v. 849, p. 424-426, 1998.

VIDOTTO, O. et al. Ocorrência de Babesia bigemina, B. bovis, e Anaplasma marginale em rebanhos de bovinos leiteiros da regiáo de Londrina, PR. Revista Brasileira de Parasitologia Veterinária, v. 4, n. 2, supl. 1, p. 184, 1995.

VISSER, E. S. et al. The Anaplasma marginale MSP5 gene encodes a 19-kilodalton protein conserved in all recognized Anaplasma species. Infection and Immunity, v. 60, n. 12, p. 5139-5144, 1992.

YOSHIHARA, E. et al. Studies of natural infection with Anaplasma marginale in Umuarama municipality, Parana State, Brazil. Revista Brasileira de Parasitologia Veterinária, v. 12, n. 1, p. 21-26, 2003. 